\title{
Communication for Development in Good and Difficult Times
}

\author{
The FAO Experience
}

\author{
Silvia Balit ${ }^{1}$
}

\begin{abstract}
The article tells the story of the evolution of communication for development within the United Nation's (UN) Food and Agriculture Organisation (FAO), describing the good times in the past as well as the difficult times in the last decade as an example of how the discipline continues to be marginalised in development institutions. The author argues that new challenges and trends demand new thinking on the part of institutions and governments, as well as new practices and skills by communication practitioners, and stresses the need to avoid re-inventing the wheel. New approaches should be married up with the participatory principles and methodologies applied in the past that are still valid for meeting the new challenges. The article concludes with a discussion of the prerequisites for an enabling environment for mainstreaming communication for development.
\end{abstract}

Keywords: communication, development, mainstreaming, participation, FAO

\section{The Marginalisation of Communication for Development}

Communication is as old as homo sapiens and has always been a powerful force in all cultures for sharing ideas and knowledge, and for influencing values and behaviour to bring about social change. Today, the so-called information revolution has provided us with an explosion of new technologies and media, and dramatically increased the potential for sharing information across the globe in all walks of life. Those technologies offer immense opportunities, and their potential can be used for positive or negative ends, for liberation or domination, for enlightenment or manipulation (Ansah 1993).

The terrible images of the earthquake, tsunami and nuclear disaster in Japan in March 2011 spread throughout the globe in real time. Between 1994 and 2005, the indigenous Zapatista movement in Chiapas was able to survive and promote its agenda thanks to the international backing received through the use of Internet and other media. No political figure today can aspire to win an election without the use of communication technology and the media, as demonstrated by Barack Obama's presidential campaign in 2008. Small farmers in rural communities in the Philippines now use mobile phones and sms messages to gain information, sell their products and keep in touch with relatives abroad. The world economy has become primarily a knowledge economy, shaped by neoliberal globalisation. Thanks to new information technologies, financial centres 
are now able to operate in real time on a global scale, bypassing national states, and creating super-national powers. Moreover, we all have witnessed the power of social networks in the Arab world, mobilising people to participate in the quest for democracy and playing a role in the toppling of dictatorial governments. In Egypt alone, some 11\% of the population are Facebook users (Socialbakers 2011) ${ }^{2}$. Protests in Tunisia starting in December 2010 were recorded on mobile phones, shared on Facebook, and eventually broadcast by Al Jazeera.

Nevertheless, when it comes to development, communication skills and technologies are still not being used as they should be by development institutions. Over the years, communication for development has made a difference in hundreds of community-based projects and programs, and many development programs have failed because they failed to communicate with the intended beneficiaries and other stakeholders. Yet, ironically, communication for development is still marginalized in the development process (Servaes et al. 2006). Communication strategies are not integrated from the start in development programs, and tend to be given too few resources. The global financial crisis has not helped: communication for development is like the fifth wheel on the cart, and the moment a budget cut is necessary, it is the first component of a project to be eliminated by program managers and planners.

In addition, there is still confusion and lack of understanding within development agencies of what communication for development is all about. Like politicians and business people, decision makers in development institutions are keenly aware of the importance of information and communication activities, but primarily in connection with public relations or corporate communication. Some still think that "communications" only refers to infrastructure, such as roads, telegraphs and faxes. If they deal with agricultural or rural development, they often equate communication with extension. In some cases, they understand the advantage of using communication in development programs, but are usually only interested in producing messages to tell people what to do, rather than in listening and giving people a voice. Governments, in turn, tend to be primarily interested in cutting edge technologies, and believe that adopting those technologies means that they are applying communication in development programs.

Communication in development goes beyond using technologies such as television, radio, mobile phones and the Internet. It has to do with people, and implies employing the most appropriate methods and tools to empower people to set their own agendas. The social networks recently used in the Middle East to enable people to participate in a quest for democracy are an example of a process of communication for social change in which communication technologies contributed to an empowering of citizens.

International development priorities, enshrined in 2002 in the Millennium Development Goals (MDGs) ${ }^{3}$, are based on reducing poverty and improving poor people's lives. Yet, there are still more than 1 billion people living in extreme poverty and suffering from hunger and malnutrition. The problems addressed by the MDGs are all people-oriented issues that require participation, dialogue and ownership if they are to be met. Thus, communication, and the experience of communication practitioners who have dealt with the poor and disadvantaged for years, are essential. However, communication is absent from the Millennium Development Goals. Decision-makers do not recognize the key role that information and communication can play in development programs. 
New and pressing challenges such as climate change, scarcity of fresh water, armed conflicts, mass migration, terrorism and religious fundamentalisms are also issues for which communication is essential. Notwithstanding many years of experience and successful examples, major development institutions have yet to mainstream the discipline and communication for development specialists are still struggling for recognition.

\section{The FAO Experience}

Throughout the 70s, the $80 \mathrm{~s}$ and up to the mid 90s, FAO was recognized as a pioneer and a leading agency in the field of communication for development. Within the UN system, UNESCO and UNICEF were also pioneers and leading agencies in the discipline.

It all started in Bangkok in 1967, when the first Development Support Communication (DSC) Service was established, with financing from the United Nations Development Program (UNDP) and the United Nations Children's Fund (UNICEF). DSC owed its vision to Erskine Childers, a long-serving and committed UN official. Childers convinced the UNDP Administrator of the importance of communication in development, and UNDP sent out a circular to all UN Agencies requesting them to include communication components in all UNDP financed projects. In 1969, units were established in various agencies, with different names but with a common consensus that communication should become a component in development programs.

It was logical to start a DSC program in FAO, since it dealt with agriculture, rural development and extension, and had a farm radio program. Interest came from the Director of Public Information rather than from the Extension Services, that were suspicious of the new discipline and considered it a competitive threat. The Development Support Communication Branch (DSC) was established in 1969, under the leadership of Colin Fraser ${ }^{4}$. DSC made use of the media resources of the Public Information Division but did not deal with public relations or institutional promotion; it was entirely field oriented. Its objectives were to improve project planning, participation and capacity development.

From the beginning, it was an uphill battle for DSC to receive recognition within an organisation that was traditionally very technical and, especially in its first years ${ }^{5}$, entirely devoted to the transfer of technology and the hard sciences. Top-down approaches were still prevalent. FAO technicians were convinced they had all the answers, and that it would be sufficient to spread the word for knowledge to trickle down and for people to accept new ideas and put them into practice. There was little experience of using communication for social change with illiterate populations in rural areas, as well as insufficient recognition of the role of traditional indigenous knowledge and culture. Agricultural information services and extension in developing countries were applying one-way approaches to disseminating technical information. There were few governments in developing countries willing to establish a true dialogue with rural people and allow decentralised decision- making to take place. The role of communication was considered as primarily limited to supporting transfer of technical knowledge, and to producing media materials for extension.

Slowly, with the change of development paradigms and a rise in the emphasis given to the human aspects of development and participatory processes, communication started being recognised as a social process to improve the lives of rural people and increase participation, in FAO and beyond. 
Initially, the DSC Branch began working pragmatically, without dogmas. No one in the group had an academic background in communication, although some had backgrounds in media or learning methodologies. Colin Fraser himself had been an instructor with the Massey Ferguson company in the use of farm machinery - he was also a born communicator. The group started learning by doing, learning from mistakes as well as from successes. The results of field programs led to increasingly creative approaches, taking into account the perceptions of rural people and their realities, and using technologies and channels that were appropriate to the social, economic and cultural conditions of rural areas in developing countries. The practical experience in the field led to the development of a number of innovative communication systems and approaches in the regions. The presence of a number of "champions" (Quarry and Ramírez 2009) as project managers also helped.

In Peru, an audiovisual training methodology based on the use of video was developed for large-scale training of illiterate communities. A holistic approach was applied with programs produced on all the themes of interest to the farm family. Attention was paid to peasant culture and traditional technologies. In Mexico, the rural communication system of PRODERITH ${ }^{6}$, an integrated rural development program, applied video to consult with communities and involve them in local development planning, and knowledge sharing was then based on needs as identified by them. Young farmers, both men and women, were trained to produce and use communication materials with their communities. Messages were produced by the farmers, with the farmers, and for the farmers. Social communication networks were established to share knowledge and experience among communities and local and national government institutions.

In Africa, based on the oral tradition, radio was considered the most effective medium to reach large numbers of rural audiences over vast distances. A participatory approach to rural radio was developed, which gave a voice to rural people. Rural radio services were brought to the villages, and programs were produced in local languages with the people's participation, in accordance with traditional customs and values, while at the same time providing them with relevant information. In several countries in Africa, the use of traditional media -local artists, music, storytellers, theatre groups and puppets- combined with qualitative research, group discussions and other participatory tools was successful to provoke change in life styles on sensitive subjects such as population issues.

In Southern Africa, a methodology for Participatory Rural Communication Appraisal (PRCA) was developed to enable change agents to involve community members in identifying problems and proposing solutions to be adopted by the community at large.

Another successful strategy was the use of multi-media campaigns to support a clearly defined and particular development strategy, such as the eradication of rinderpest, a deadly cattle disease in Africa, or pest control in Asia. Campaigns combined interpersonal and multi-media channels in an orchestrated and mutually reinforcing manner. Techniques such as audience research, pre-testing of materials, and message fine-tuning were used on the basis of feedback and evaluation.

After some twenty years of pragmatic field experience, it was considered important to formalize FAO's approach to communication for rural development, and an Expert Consultation was organized in 1987 for that purpose. Participants included academics as well as communication specialists from all regions. The consultation was a true milestone in FAO's experience. It contributed to a better understanding of the role of 
communication in agricultural and rural development, provided directions for future work and defined a strategic framework and guidelines that are still valid today, and useful not only for FAO but also for other organizations.

\section{Some Reasons for Success}

There were a number of reasons for the success of the FAO communication program that could usefully be taken into account in current efforts to mainstream communication for development in development agencies (Balit 2011).

As a result of the Expert Consultation held in 1987, a strategic approach was applied that ensured that FAO communication activities at Headquarters and in the field followed a common vision, and took into account the guiding principles and prerequisites developed.

Although the Communication for Development Branch was initially located in FAO's Information Division, the discipline was an officially recognised sub-program of the FAO Economic and Social Program, and the activities of the Branch were presented to the organization's governing bodies for supervision and review of its program of work and budget. Thus, communication for development was an integral component of the policies, programs and budget of the organisation.

The Branch had a large field program, with projects that were able to supply evidence of the added value of communication for development. Projects lasted five to ten, even fifteen years. As a result, it was possible to develop innovative and sustainable communication methodologies. The results were documented with case studies that were distributed widely. There were skilled and committed project managers, "champions" for communication for development. Over the years, three field experts were awarded the B.R. Sen Award, given at the biennial FAO Conference to the best field expert. The awards were given to Paul Daniel for rural radio in Dahomey (now Benin), to Manuel Calvelo Rios for audio-visual pedagogy in Peru, and to Santiago Funes for the PRODERITH rural communication system. This helped immensely in terms of attaining recognition of communication for development within the organisation.

The field experts had capacity building and local ownership as their main objectives, building local and national structures that would be sustainable even when the international projects ended. Respect for local traditions, language and culture were paramount, as was a gender perspective. In the majority of projects, half of the national staff were women. This was the case also for the program at Headquarters. Many of the national staff members, trained by the international experts, went on to initiate and implement similar projects in developing countries ranging from Bolivia and Chile in Latin America to Mali and Equatorial Guinea in Africa to China and Korea in Asia.

The results of projects and programs were shared regularly with other divisions and departments within FAO. Over the years, a number of supporting multi-media materials including booklets, slide sets and the professional video "Sharing Knowledge" were produced. The video was presented to the highest policy level board within the organization, including the Director General and all Assistant Director Generals. The case studies and publications produced were widely distributed beyond FAO to other UN agencies, member governments and NGOs.

The Branch had a critical mass of staff, up to nine professionals, as well as general service supporting staff. The staff had expertise in different aspects of communication 
ranging from audiovisual media, rural radio and ICTs to planning, research and evaluation. Staff travelled frequently to field programs not only to ensure supervision and dialogue, but also to formulate new projects with local stakeholders in line with country needs. The staff at Headquarters was committed to the cause, and together with the field experts created a community of practitioners, sharing experiences and methodologies.

\section{The World Congress}

The World Congress on Communication for Development, held in Rome in October 2006, sponsored by FAO, the World Bank and the Communication Initiative, was an important event in the history of institutionalized communication for development. "Without communication there is no development" was the event's message, aimed at demonstrating to policy makers that communication for development is an essential tool for meeting today's most pressing development challenges, and therefore should be more fully integrated into development policy and practices. The meeting brought together some 900 participants from around the world to share experiences and best practices. The many voices at the Congress were evidence of how the discipline has evolved, the variety of people and institutions now working in this area, and the richness of theories and practices in the field. During the course of the debates, there were points of difference but also agreement on many issues. The Rome Consensus adopted by the Congress provided a definition of communication for development that is now commonly used by UN agencies, which recognizes communication for development as a social process, based on dialogue and using a broad range of tools and methods (Rome Consensus 2006) ${ }^{7}$. Such common understanding was expected to help in efforts to mainstream the discipline within development institutions.

However, following the Congress both the World Bank and FAO failed to strengthen their communication for development programs as called for by the Rome Consensus. Thus, the event did not succeed in its objective of advocacy with policy makers among two of its sponsors. The World Bank underwent changes in senior management, and rather than give sufficient importance to ComDev, the new managers gave priority to strengthening corporate communication. As for FAO, a reform and restructuring process was taking place at the time of the Congress, and it has been argued that without a Senior Officer/Chief the ComDev group was unable to defend the discipline with senior management during the restructuring process.

\section{Difficult Times}

Considering the positive experience of the FAO ComDev program in its first twentyfive years, why was the discipline not recognised as it should have been during the FAO reform and restructuring process? Why is it still marginalised in the organisation's renewed agricultural and rural development system to date? There were a number of factors, some related to context and not confined to FAO alone (Balit 2011). To begin with, an enabling environment for communication for development did not exist in the last decade. Compared to the ' $80 \mathrm{~s}$ and the beginning of the ' $90 \mathrm{~s}$, the global and rural development context changed considerably at the end of the ' $90 \mathrm{~s}$ and the beginning of the $21^{\text {st }}$ century. It became less favourable to social programs such as communication 
for development. Structural adjustment programs were prevalent, with less attention to social issues and assistance to poor and vulnerable groups. Governments and traditional rural institutions withdrew from certain functions that were taken over by the private sector. Globalisation started shaping the world economy, and privatized public services, free markets and international trade agreements created new scenarios for development with serious effects on governments, rural institutions, local communities and vulnerable groups. Multinationals and agribusinesses dominated the scene, buying up land and cultivating crops for export.

Communication is essentially participation. However, notwithstanding the hype about participatory processes in development programs, few donors, organizations or governments really promote people's participation and social change. Participatory approaches are still relatively new in many organizations, including FAO, and the successful results of participatory practices in the field would have needed to be shared and made known more widely. Furthermore, the vertical structure of institutions and the operational mode of most organizations based on results-based management and project logical frameworks are not conducive to participatory approaches. Participation will upset preset objectives and any well-defined timeline, while donors want quick results. Moreover, administrators and politicians in central governments, though they will not admit it, rarely care about the needs of communities in the periphery, nor do they wish to relinquish power as a result of true participation.

Many organizations still confuse communication for development with corporate communication and public relations, allocating most financial resources to the latter. In some cases, such as in the World Bank, there is a deliberate choice to favour corporate communication. During the FAO reform process, Public Information was renamed Corporate Communication, and a series of information officers' posts were relabelled as communication officers, fostering the persistent misunderstanding between communication for development, corporate communication, and information.

The global financial crisis did the rest: with fewer resources available for development, competition for funding of projects became tough. It was difficult to find resources for ComDev to finance field programs with sufficient duration to obtain sustainable results and including funds for research and evaluation. Insufficient monitoring and evaluation in turn resulted in lack of sufficient data to provide concrete examples of impact and to demonstrate the value of communication to policy makers with backgrounds in the hard sciences.

Although at the beginning of the $21^{\text {st }}$ century there was great interest on the part of donors and governments in new information and communication technologies, it was primarily in the technologies per se, and not as tools in a social process. Institutions like FAO gave priority to "bits and bytes", and knowledge management became the new frontier.

The institutional framework for ComDev continues to be problematic ${ }^{8}$. The debate remains the same: should the discipline be located in a media division or in a substantive program division?

Within FAO, over the years ComDev underwent a series of different institutional placements. For the first twenty-five years, it was in the Public Information Division as an autonomous Branch. In 1991 the name was changed to Communication for Development following the suggestion of a UN Roundtable meeting sponsored by FAO to use 
the term communication for development throughout the UN system. In 1994, it was transferred to the Research, Extension and Training Division in the newly established Sustainable Department, still as a Branch. This was considered a good move, since it reflected the cross-cutting and technical nature of the program and avoided confusion with public information. In 1996, the Branch was merged as a Group within the Extension, Education and Communication Service. Following the FAO reform and restructuring process, the remaining officers were incorporated as a Group in the Research and Extension Branch under the Office of Knowledge Exchange, Research and Extension, where they are today. Being under the Office of Knowledge Exchange may be positive, but ComDev no longer exists as such in the FAO organigram, and the term can only be found in the titles and terms of reference of the three officers in the Group. The old belief that ComDev is primarily a support to extension has prevailed.

Although struggling with institutional problems and limited resources, the FAO ComDev Group has maintained a dense program of activities. An Expert Consultation, "Communication for Development: meeting today's agriculture and rural development challenges", organised in September 2011, is an example of how the Group is looking towards new trends and challenges of the future, striving to reintegrate the discipline as an essential component in the organisation. The preparation of a Corporate Strategy on Communication for Development is a major priority in a road-map approved by the Consultation for mainstreaming the discipline.

\section{Lessons Learned - Some Essential Guiding Principles}

Notwithstanding institutional ups and downs, the results of practice in the field and evaluations carried out by communication scholars across the globe in the last forty years have confirmed a series of essential guiding principles. These should not be forgotten, even though new challenges require new approaches and adaptation to a changing world.

\section{- Starting upstream}

To be effective, communication should be built into development programs and policies from the start and integrated into development policies and poverty reduction strategies together with the participants and all stakeholders. A communication strategy planned with participants from the start will ensure their active involvement and ownership, and give development programs better chances of being successful and sustainable.

\section{- A social process}

Communication for development was defined by the FAO Expert Consultation held in 1987 as "a social process, designed to seek a common understanding among all the participants of a development initiative, creating a basis for concerted action." Communication technology and the media are useful tools to facilitate this process, but should not be considered as an end in itself. What is important is the process, rather than the product or the technology/media used (FAO, 1987). Interpersonal communication and the participation of a community change agent as a facilitator or broker with the rural community remain essential. Whenever possible, communication programmes should be produced with and by rural people themselves, about their social problems and 
perceptions, and not just by outsiders. The professional quality of the product is not as important as guaranteeing local content in the production process.

\section{- Sharing of knowledge and two way communication}

The experts at the first FAO Expert Consultation indicated that "people oriented and sustainable development can only realise its full potential if rural people are involved, and if information and knowledge is shared. Sharing is not a one transfer of information; it implies rather an exchange between communication equals" (Balit, 1999). In 1989, Colin Fraser visited the areas covered by PRODERITH and met many of the participating communities, organizations and individuals. There he discovered what, to his mind, was one of the most important methodological "secrets" of the Mexican experience: "The main challenge faced by a good communication system in the field is not, as one might generally think, filling a social space with words; it consists in the establishment of an initial silence, where the actors present recognize each other as equals, with the same rights and possibilities for generating the new knowledge required to improve the quality of life and working conditions" (Funes, 1996).

\section{- Listening to people}

Thus, communication for development efforts should begin by listening to people, learning about their perceived needs, taking into account their knowledge and experience, their culture and traditions and the reality of rural areas. Listening is an important skill developed by oral cultures that rely exclusively on oral communication. Dialogue also requires the capacity to listen and to be silent. However there is still much to be done in terms of training in participatory communication methods and changing the attitudes of field staff and development agents who have been educated to apply top down, authoritarian methods and tell people what to do. Fortunately today there are many participatory research and diagnostic methods that have been developed to listen and learn from communities, such as Knowledge, Attitudes and Practices (KAP) surveys, Participatory Rapid Appraisal (PRA), Participatory Rural Communication Appraisal (PRCA), focus group discussions, ethnographic research, etc. These methods ensure that the needs of beneficiaries are taken into account in the planning of projects, and that monitoring and evaluation makes use of qualitative indicators identified with the communities themselves.

\section{- In line with national policies}

Communication policies and strategies should be designed in accordance with national policies for poverty reduction and sustainable development and help to promote them. Otherwise, communication strategies and programmes will remain isolated and not receive the support of national policy makers and decision-makers. A key characteristic of the PRODERITH rural communication system in Mexico was its placement within a public policy where participation was prevalent. This helped its development and is crucial to understanding the causes of its success (Funes, 1996). National communication policies have been introduced in a number of countries in the West and Central Africa region to articulate and regulate the role of communication in development. They have 
proposed different institutional frameworks for the discipline, bringing together the variety of ministries and stakeholders involved in poverty reduction and development programs.

\section{- Promoting policy change}

Communication for development also has an important role to play in enacting and promoting national policy change, since there is a tendency to move away from top down policy planning towards more participatory and interactive processes of policy planning, adjustment and implementation. Country programs now concentrate on community participation and ownership, and communication can foster the required dialogue between policy makers and communities. There is also the need to build governmental receptivity for sustainable development and poverty alleviation issues, and to engage civil society and the business community. In this respect, advocacy through the media can play a key role for the establishment of new legislation or for promoting the implementation and/ or enforcement of an existing one.

\section{- Holistic approach}

Communication is a multidisciplinary and cross-cutting discipline. Thus, efforts should cover all the multifaceted aspects of life that concern poor people and their livelihoods. Communication activities should deal with agriculture, health, habitat, education, nutrition, the environment, population, gender, and all issues related to development. Communication can provide the necessary linkages that will ensure coordinated management for multi-disciplinary programs that involve a number of development sectors and subject-matter ministries.

\section{- Preserving indigenous knowledge, values and culture}

It is important to incorporate indigenous knowledge and practice in the planning of communication for development projects: "The outcome of useful sharing of knowledge is not so much the replacement of traditional techniques by modern ones, as a merging of modern and traditional systems to produce a more appropriate hybrid, one that befits the economic and technical capacities of rural populations as well as their cultural values" (FAO,1987). Indigenous knowledge can provide an understanding and analysis of a situation that will ensure that programs are formulated in harmony with the environment and relevant cultural issues. Indigenous groups have access to a large volume of traditional knowledge about their environment and are highly efficient users of available resources that have been crucial for their survival.

\section{- Respect for culture}

Communities in rural areas contain a wealth of traditional cultural resources, a rich but fragile heritage which risks being lost with the advent of modern technology. The tendency to cultural homogenization that comes with globalization processes can erase cultural identities and diversities. To be successful, communication efforts must take into account the values of rural people rather than borrowing communication strategies from outside that promote change without due consideration for culture (Decock 2000). 


\section{- Shared interests and trust}

Shared interests and trust are also essential elements of the communication process. Shared interests are the cohesive force in social networks and can explain the evolution of such formations. The ideal sharing of interests is expressed by the achievement of a social consensus, and a state of mutual trust. Trust and credibility are also closely associated. It is well known that the effectiveness of a medium or a communicator hinges on their credibility and trust. For rural people, communication is still about building personal relationships, and when it comes to building trust and collaboration, face-toface communication remains the preferred channel (Fugelsang 1987).

\section{- Flexibility and duration}

Social change and participatory communication processes take much more time than the typical 3-5 year project cycle during which governments and donors usually wish to obtain quick results. The most successful communication programs have had a duration of seven to ten years, with a long term perspective. The development context is dynamic, with unanticipated events and variables that are difficult to predict. Communication can produce lasting and successful results when it is part of a flexible approach in designing projects, where the whole endeavour is planned, executed and evaluated with the participants, and when there is sufficient time and flexibility to allow for changes in direction as the project develops.

\section{- Ensuring gender sensitivities}

The empowerment of rural women through the sharing of information, knowledge and communication is crucial for achieving development goals. However, women are often underestimated and overlooked in development strategies, and remain the "invisible" partners in development. They belong to the culture of silence. Activities and materials should reflect the special needs and preferences of women, and address the social, economic and cultural constraints they face in the design of communication messages, choice of appropriate channels, and best timing and locations for delivery. Women in rural areas have communication requirements that are different from those of men. They do not have equal access to information, due to factors such as restricted mobility outside the home, lack of education, and sometimes men's control over information or media technology. Because women are involved in many aspects of rural life, their traditional knowledge systems are holistic and multi-disciplinary. For generations they have relied on the spoken word and traditional forms of communication as a means of sharing knowledge and information. They have made use of the oral tradition to develop a rich communication environment, transmitting culture, knowledge, customs and history through traditional forms of communication such as poetry, proverbs, songs, stories, dances and plays. Within their communities they are active participants in social communication networks, using indigenous communication methods to disseminate knowledge and strategies for mutual assistance and survival (Balit 1999). More generally, communication programs should always include a gender perspective. A new issue on the development agenda is the increasing violence that women are subject to in situations of conflict and post-conflict. 


\section{- Multimedia approach}

Communication initiatives should make use of all media channels available, both modern and traditional, in an integrated manner. The advent of new technologies now means that new mixes can be made, to create more effective communication programs with disadvantaged groups. And, in some cases, using traditional channels and methods that rural people are familiar with and know how to use can provide the most effective solution to information sharing and dialogue.

\section{- Political space and context}

Communication for development is contextual. There is no universal formula capable of addressing all situations, and therefore communication for development should be applied according to the cultural, social and economic context. As a process of empowerment, when dealing with political and social injustices, participatory communication approaches can only take place if there is political space and will on the part of government and local authorities. Otherwise, the local people will pay the price. An example of best practice in this sense is the PRODERITH program, which flourished when participatory approaches were part of the government policy. When the government changed its policies, the project was forced to implement traditional communication activities for the transfer of technology (Fraser, Restrepo 1996). Authentic participation directly addresses power and its distribution in society, and usually authorities do not want to upset the status quo, even if they pay lip service to participation. In another example, a successful rural radio project implemented by FAO in Angola was closed down by the government when the radio started giving space to the demands of the local population. Good governance, transparency, respect for freedom of expression and human rights are essential prerequisites for successful participatory communication approaches. Shared values, commitment and will on the part of the communities involved are also essential prerequisites.

\section{- No off-the-shelf solution}

There is no single model for planning successful communication strategies and programs, since they deal with people, and not only with technology. Every situation is different -different audience groups, their location and distribution, their languages, their characteristics and needs, their levels of education, their access to the media, and their existing attitudes and behaviour. Each group of users has a different cultural approach to information, whether they are from different regions, countries or neighbourhoods. One must tailor an information/communication activity to each group's needs and preferences. The communication objectives will be different, as well as the media that are available or most appropriate. Every situation calls for an analysis, audience research and a strategic communication plan to implement a successful communication program.

\section{New Directions}

What are the chances that communication for development be recognised and mainstreamed in development institutions in the future? Is there an enabling environment for the discipline? The international context has again changed. The development com- 
munity is seeking new approaches to overcoming the failures of the last decades, and there are many voices calling for "another development". The challenges are complex, and there are conflicting views on major issues such as climate change, food as fuel (biofuel), new technologies underlying food production and the sustainability of global and local food systems (Hambly 2011).

Apart from the overriding commitment to eradicating poverty, agricultural and rural development, natural resource management and climate change are again priorities on the development agenda. The recent emergency in the Horn of Africa, with millions dying because of drought and lack of food and water, has mobilised the international donor community. The challenges and emergencies are so great that the international community is again supporting public agricultural policies in developing countries and discussing new investments to promote the development of rural areas. Donors and development agencies are coordinating their efforts, and demanding that ownership, dialogue, participation, and transparency become essential components of their programs. Contrary to the past, small farmers are now considered protagonists in fighting hunger and the deterioration of ecosystems and climate change.

These are all approaches that communication for development has privileged as part of its philosophy and practice when working with marginal and vulnerable communities. And today the marriage of new information and communication technologies with more traditional channels such as radio has increased the potential and suitability of communication media to reach distant audiences and work with the disadvantaged. Social media and communication networks are enabling people to voice their demands and promoting major changes in developing countries that governments can no longer ignore.

The recent UN Inter-Agency Round Tables on Communication for Development ${ }^{10}$ have identified the priorities for mainstreaming the discipline within the UN system, and are addressing issues such as advocacy with decision-makers, monitoring and evaluation methods, and capacity building at all levels - this is an important priority because of the need for training in institutions as well as countries. One of the reasons for the marginalisation of the discipline is the lack of qualified communication planners in development institutions and in governments capable of dialogue and advocacy with policy makers. The increasing number of universities providing graduate programs in ComDev throughout the world will hopefully help to overcome this problem.

New and complex problems, such as climate change, scarcity of fresh water or mass migrations, call for innovative communication approaches and a retooling of communication skills. According to Chin Saik Yoon, "The severity of the challenge to communication practitioners comes from the complexity of the problems posed by these "new" issues, many of which have no ready solutions for communication and action, and are without precedence. They will be the big challenges of practice in the generations to come" (Saik Yoon 2010).

Future generations of communication practitioners will need to develop new processes of practice to address the challenges these issues pose. The solutions will require involving multiple stakeholders and civil society, in addition to traditional partners. However, in the search for new approaches it is important not to forget the successful methodologies and experiences of the past that can still contribute to finding solutions to these issues. It is important not to re-invent the wheel. Within the discipline of communication, the accumulated experience with participatory communication with the poor 
and disadvantaged contains many principles and methodologies that are still valid for meeting new challenges. Communication practitioners will need to draw upon the best practices and lessons learned in the past and merge them with new communication methods and approaches to meet the changing needs of the global society. Essential elements for successful and sustainable efforts will continue to be dialogue, ownership on the part of communities and integration with existing indigenous communication systems.

Today's challenging times also demand fresh thinking and action on the part of development institutions and governments. The question is: can governments and local authorities go beyond the hype surrounding participation and enter into a true dialogue with rural communities and vulnerable groups? Can donors and development agencies accept participatory approaches in the field that may not follow pre-set objectives or precise timelines? Can development programs be planned with sufficient duration, budgets and evaluation criteria to produce sustainable results and social change? The mainstreaming and future of ComDev as an essential component in development programs is dependent on institutions and governments meeting these requirements. And more importantly, the poor and disadvantaged can no longer wait.

\section{Notes}

1. Silvia Balit, from Italy, is a Communication for Development consultant. Together with Colin Fraser she pioneered ComDev activities in FAO in 1969, and was Chief of FAO's ComDev program from 1984 to 1998. E-mail: mc8918@mclink.it

2. Figure provided by Socialbakers, a portal for social media statistics (www.socialbakers.com)

3. See http://www.un.org/millenniumgoals/.

4. See Balit (2009) "Remembering Colin Fraser", Glocal Times \# 12. Available online at http://webzone. k3.mah.se/projects/gt2/viewarticle.aspx?articleID=159\&issueID=19

5. FAO was created in 1945 .

6. Programa de Desarrollo Rural Integrado del Trópico Húmedo (Program of Integrated Rural Development of the Human Tropic).

7. For the full text of the Rome Consensus and the deliberations of the Congress see: www.devcommcongress.org/world bank/public.asp

8. Within the UN system, from the beginning UNESCO has been an exception and has benefited from the fact that communication is part of its mandate, and vision. Thus, information and communication have been recognized as a sector, and integrated in policies, work and budget, with a critical mass of professional staff. Recently, UNICEF has revitalized ComDev. The discipline has been recognized as a key cross-cutting strategy in UNICEF's Medium-Term Strategic Plan, and at Headquarters a Communication for Development Unit is now strategically located within the Policy and Practice Group.

9. See http://www.fao.org/oek/communication-for-development/expert-consultation/en/

10. See http://portal.unesco.org/ci/en/ev.php-URL_ID=21347\&URL_DO=DO_TOPIC\&URL_SECTION=201.html

\section{References}

Ansah, P. (1994) “An African Perspective" in Nostbakken, D. And Morrow, C. (eds.) Cultural Expression in the Global Village. Penang: Southbound.

Balit, S. (1999) Voices for Change: Rural Women and Communication. Rome: FAO.

Balit, S. (2011) New Directions for Mainstreaming Communication for Development in FAO.

Decock, A. (2000) “Tapping Local Cultural Resources for Development” in Servaes, J. et al (eds.) Walking on the Other Side of the Information Highway: Communication, Culture and Development in the $21^{\text {st }}$ Century. Penang: Southbound.

FAO (1987) Report of Development Support Communication. FAO Expert Consultation. Rome: FAD.

Fraser, C. \& Restrepo-Estrada, S. (1996) Communication for Rural Development in Mexico: In Good Times and in Bad. Rome: FAO. 
Fugelsang, A. (1987) The paradigm of communication in development: from knowledge transfer to community participation - lessons from the Grameen Bank, Bangladesh. Rome: FAO.

Fugelsang, A. (1982) About understanding - ideas and observations on cross-cultural communication. Uppsala: Dag Hammarskold Foundation.

Funes, S. (1996) Introduction to Fraser, C. \& Restrepo-Estrada, S. Communication for Rural Development in Mexico: In Good Times and in Bad. Rome: FAO.

Hambly, H. (2011) "Communicative Actions and Agency in Issues of Global Food, Agriculture and Environment”. Presentation at the 2011 Ørecomm Festival. Malmö: Ørecomm Consortium for Communication and Glocal Change.

Mafeje, A. (1974) “Communication for Whom”, in Ideas and Action Bulletin n. 95. Rome: FAO.

Saik Yoon,C. (2010) "Future Imperatives". Paper presented at the International Conference on Future Imperatives of Communication and Information for Development and Social Change, Bangkok, December 20-22.

Servaes, J. et al (eds.) (2007) Communication for Development: Making a Difference, a WCCD Background Study. The Communication Initiative, FAO and The World Bank.

Quarry, W. and Ramírez, R. (2009) Communication for another Development, Listening before Telling. London: Zed Books. 